\title{
Effective Work Place Training: A Jump Starter to Organizational Competitive Advantage through Employee Development
}

\author{
Sri Divya K. \\ Research Scholar, VIT Business School, Vellore, Tamil Nadu \\ Sridivya554@yahoo.com \\ S. Gomathi \\ Senior Professor, VIT Business School, Vellore, Tamil Nadu \\ sgomatthi@vit.ac.in
}

\section{Doi:10.5901/mjss.2015.v6n3p49}

\begin{abstract}
Workplace training programs are usually considered to be an important element of the competitive organization's corporate strategy. It presents a key avenue to expand the knowledge base of all employees and provides both the company as a whole and the individual employees with benefits that make the cost and time a valuable investment. Most employees have some weak spots in their workplace skills providing them continuous workplace training creates an overall employee development. Further employees who are competent and on top of dynamic industry standards help in overall organizational growth and aids in company to hold a position as a leader and strong competitor within the industry. This paper is broadly categorized in two parts. The first part tries to explore the meaning of workplace Training, Its impact on Organizational Competitive advantage. It also emphasizes how employee development in turn impacts organizational Competitive advantage. This paper suggests model framework in which its main aim is to show how Workplace Training has impact on organizational competitive advantage through Employee development.
\end{abstract}

\section{Introduction}

In a today's challenging global scenario, both behavioral and technical skills of employees are the most important assets for organizations to determine their competitiveness and competence to adapt and be hands-on when faced with an uncertain environment. An employee who possesses the necessary skills, knowledge and expertise is crucial for any organization who wants to achieve high levels of business success. In our current challenging and competitive business environment, workplace Training and development has been more important as an aid to keep employees engaged and maintain that competitive advantage. Training has the distinctive role in the achievement of an organizational goal by integrating the interests of organization and the workforce.

Now a day's training is the most crucial factor in the business world because training increases the efficiency and the effectiveness of both employees and the organization. The employee performance depends on various factors but the most significant factor of employee performance is training. Training is important to boost the capabilities of employees. The employees who have more on the job experience have better performance because there is an increase in the both skills \& competencies. The organizational performance depends on the employee performance because human capital of organization plays a vital role in the growth and the organizational performance. So to improve the organizational performance and the employee development, training is given to the employee of the organization. Training is a key tactic for developing skills in people, since it aids them to both learn and unlearn skills - in other words, to acquire new skills and change inappropriate skills.

Training may be defined as the organized acquisition of skills, concepts, or attitudes that shall further result in superior performance of the trainee. Workplace training is important in today's knowledge-based economy. Workplace training is necessary to help employees widen and use the skills they need to acclimatize to changing workplace needs, to endorse innovation and to help employers remain competitive in the global marketplace. Finding and keeping employees with the knowledge and skills to get the job done is critical in today's workplace. A skilled workforce is often the asset to a company's growth and stability, and it could be the influential factor in the success of organization. 
Improving the essential skills of workers has remarkable impact for both the employee and employer, including higher retention rates, improved performance and Employee productivity.

Employees who participate in workplace training programs increase their level of self-confidence, acquire new skills, are better prepared to seek promotion opportunities, and believe that they are valued by their organization. A training program aids in strengthening those skills that each employee needs to perk up. This brings development of employees to a higher level so they all have similar skills and knowledge. This helps reduce any weak links within the company who rely heavily on others to complete basic work tasks. Providing the necessary training creates an overall knowledgeable staff with employees who can take over for one another as needed, work on teams or work independently without constant help and supervision from others.

An employee who undergoes the necessary training is better able to perform her job. The training may also build the employee's confidence because they have a stronger understanding of the industry and the responsibilities of their job. This confidence may push them to perform even better and generate new ideas that help them to excel. A planned training and development program ensures that employees have a consistent experience and background knowledge. Employees with access to training and development programs have the advantage over employees in other companies who are left to seek out training opportunities on their own. The investment in training that a company puts projects the employees they are valued. Employees who feel valued and challenged through training opportunities may feel more satisfied towards their job. Therefore workplace training is considered as profitable for both employees and the organizations in which they work and it Connects employee to opportunities to develop skills and abilities on an ongoing basis means that organization will be prepared to respond to changing circumstances. However, if training and development is to make a significant impact on organizational performance, employees must see the benefits to themselves of undertaking training activities.

\section{Review of Literature}

In the existing scenarios, employee training and their development have outmost importance for the sake of enhancing the productivity, which leads towards gaining competitive advantage. However, employee training is considered as the planned step towards facilitating employees to seek job- related knowledge including behaviors and skills by Dennis and Griffin (2005).Training is a type of activity which is planned, systematic and it results in enhanced level of skill, knowledge and competency that are necessary to perform work effectively (Gordon, 1992).

Oatey (1970), states training perks up a person's skill at a task. Training helps in socially, intellectually and mentally developing an employee which is very vital in facilitating not only the level of productivity but also the development of personnel in any organization. The training and development of the employees has direct offerings in the high achievements of organization which shows better performance. Training increased the organizational performance which predicted by many researches Niazi, (2011).Adeniyi (1995) states staff training and development is a work activity that can make a very important contribution to the overall effectiveness and profitability of an organization. Performance can be defined as the achievement of specified task measured against predetermined or identified standards of accuracy, completeness, cost and speed. In an employment performance is considered to be the accomplishment of a commitment in such a way that liberates the performer from all responsibilities framed down. Efficiency and effectiveness are ingredients of performance apart from competitiveness and productivity and training is a way of increasing individual's performance (Cooke, 2000). Kenney et al., (1992) stated that employee's performance is measured against the performance standards set by the organization. Good performance means how well employees performed on the assigned tasks. In every organization there are some expectations from the employees with respect to their performance. And when they perform up to the set standards and meet organizational expectations they are believed good performers.

There is a positive relationship between training and employee performance. Training creates benefits for the employee as well as the organization by positively influencing employee performance through the development of employee knowledge, skills, ability, competencies and behavior (Benedictaand Appiah, 2010). It is obvious that training plays a vital role in the development of organization, improving performance as well as increasing productivity, and ultimately putting companies in the best position to face competition and stay at the top.

Chris (1996) Training and development aim at developing competences such as technical, human, conceptual and managerial for individual and organization growth. Seyler et al. (1998) states in this continuous changing scenario of business world, training is an effective measure used by employers to complement employees' knowledge, skills and behavior. Akinpeju (1999) the process of training and development is a continuous one. The need to perform one's job efficiently and the need to know how to lead others are adequate reasons for training and development and the desire to meet organizations objectives of higher productivity. Isyaku (2000) states the process of training and development is a 
continuous one. It is an opportunity to acquire more and fresh knowledge and develop the further skills and techniques to function successfully. Tan et al. (2003) states companies are making enormous investments on training programs to prepare them for future needs. The researchers and practitioners have constantly emphasized on the importance of training due to its role and investment.Stavrou et al., (2004) focuses on the main goal of training is to provide, attain and develop the necessary skills in order to help organizations achieve their goals and create competitive advantage by adding value. Glance et al. (1997) stressed that workforce trainings helps the employee commit with the organizations and motivate the employees to perk up their work performance. Stephen \& Bowley (2007) focus on the outcome of capital invested on training processes that further raise the efficiency of the employees and the organization.

According to Pitfield (1982) the objectives of training are to: provide the skills, knowledge and aptitudes necessary to undertake required job efficiently and develop the employees so that if they have the caliber they may progress, increase efficiency by reducing errors and risks.

Nadler has shown specific benefits that an organization receives from training and developing its workers, including: Increased performance, reduced employee turnover, increased efficiency resulting in financial gains, Decreased need for supervision.

Training is an best way to learn a job and it helps employees to improve their skills to do their duties better than before, and employee development(Noe, 1999).Training and development programs can advance employee's skills and attitudes at all levels to maximize enterprise effectiveness. (Holton et al 1996). The aim behind training employees is achieving cost effective high performance and good performance brings quality, as according to Deming, (1982), higher quality of employee services implies lower costs and increase their productivity, which in turn provides the firm with a greater market share and enhanced competitiveness levels.

There are several methods of training used in the workforce: learning principles and instructional techniques (Alvarez at el., 2004); goal setting (Holton, 2005) and self-management and decline anticipation strategy or policy (Thinner et al., 1991). Therefore, organizations should prepare their training programs much in advance Rautalinko \& Lisper (2004) claim that certain programs are designed to prompt specific reasons while others apply to improve strengths and overcome weaknesses of employees before training. The two types of trainings are Behavioral Training which is conducted to improve the work place behavior of employees; and the technical training which is conducted to enhance specific skill or techniques that are used in their day to day functioning.

Successful and effective job trainings largely impact the productivity of employees during their present job. If an employee feels well-trained, they automatically commit to the organization.

Coho \& Bowleg (2007) mentioned some of the most noticeable independent variables affecting training and development. These factors include: training design, trainers quality, and learner's experience from the training session. The quality of training is generally influenced by the trainer's experience, knowledge and motivation. Course design of training specifies whether the training is designed for on-the-job, off-the-job, or whether the course is rather specific or general in nature. An employee's level of confidence reflects the efficiency and effectiveness of the training which further increases the competitive advantage of organization.

Many researchers and practitioners have harassed the significance of the learning organization as a plan to improve performance, and as the only sustainable competitive benefit for organizations. Responding to an increasingly unpredictable and turbulent business environment emphasis has also been placed on effective training and specifically on transfer of training as a strategy for competitive advantage. The confused environment has increased stress on transfer of training because organizations are forced to restrain performance in competitive environment.

\section{Proposed Framework}

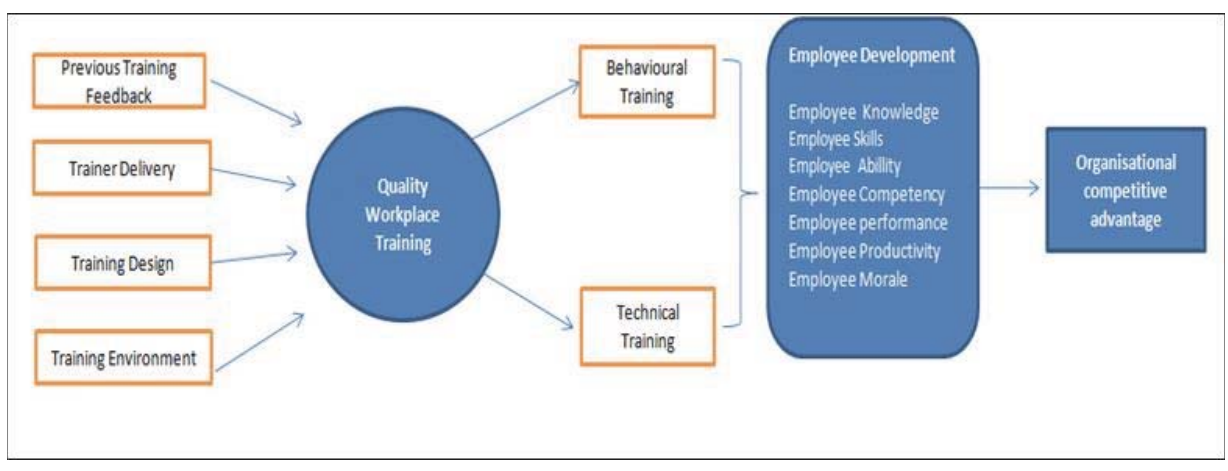


In the literature review, it has been observed that training has an impact on different variables like Employee KSA development, Employee productivity and Employee Performance. Organizational competitive advantage ultimately depends upon employee development and training is a tool to improve employee performance and their overall development in workplace.

The above theoretical framework has been formulated to depict a relationship between workplace training and organizational competitive advantage, in the presence of moderating variable Employee development.

This research has resulted in developments of training model that depicts the influence of workplace training elements on employee development and in turn its impact on organizational competitive advantage. This model was created with the review of Prior studies and theoretical models on training,

Independent variable of the study is Quality Workplace training while the dependent variable is Organizational Competitive advantage with Employee development as moderating variable.

\section{Workplace Training Consisted of Four Dimensions Namely}

1) Previous Training Feedback

2) Trainer Delivery

3) Training Design

4) Training Environment

Further the workplace training has been subdivided into two types of trainings

a) Behavioral Training: This training program helps in nurturing the corporate behavioral aspects of employee like Team management skills, Conflict management, and positive outlook towards challenging works.

b) Technical Training: Contrary to above training this aids in developing the specific techniques or skills that are required for better understanding and execution of day to day works and also specific technology related tasks.

Further as a planned attempt by an organization to facilitate employee learning, training enhances employee development by increasing employee KSA's,improving performance and productivity Furthermore, organizational training activities are recognized as being able to become sources of competitive advantage (Barney, 1995) through their impact on employee overall development ( $\mathrm{Ng} \& \mathrm{Siu}, 2004)$.

\section{Limitations}

This model is not yet tested in industry however author believe that this research has lead to the development of model that addressed the barriers of previous models. Further research needs to be carried out to test the model.

\section{Conclusion}

We consider the point of view that training leads to important benefits to employees and organizations .The present review suggests that these benefits range from employee development to organizational competitive advantage. Certain factors like training design, delivery, environment and evaluation were used in the current research to represent their importance in training.

Further in the current competition and market related pressures, organizations need to recognize the benefits of training quicker and faster. Research on this issue is lacking in the scholarly literature; work is desired regarding the factors that can speed up the realization of the benefits of training at various levels of analysis. Prior research has focused on the relationship between linking a training program and employee learning or performance but has paid less attention to relationships between training and competitive advantage to organization. Training is a key element for improved performance it can increase the level of individual and organizational competency. Training need is any deficit in employee performance, or potential performance which can be remedied by appropriate training. There are many ways of overcoming weaknesses in human performance at work, and training is one of them. Training enhances skills, competency, and ability and ultimately worker performance. It is followed that organizational success relied on the skills and abilities of their employees, and this means that organizational success depends to an extent on considerable and continuous investment in training. This would ensure an adequate supply of employee that is technically and socially skilled and capable of being developed into expert for the departments or management positions.

Training and development eventually upgrade not only the performance of employees but also of the organization. It has been rightly said, employee development is the key to sustain organizational development and its competitive 
advantage. The 21st century will belong to those organizations which are able to learn faster than their competitors. Training improves the drive, initiative and quality of work of the employees thus assist them to be more committed to achieving the goals and objectives of the organization and this has the tendency of enhancing effectiveness among employees within the organization.

\section{References}

Adeniyi, O.I. (1995) "Staff training and development" in Ejiogu Reading in Organizational Behaviour in Nigeria, Lagos. pp. 159-167.

Barney, J. B. (1995), "Looking inside for competitive advantage", The Academy of Management Executive, 9, 4, pp 49-61

Benedicta Appiah April, (2010), "The impact of training on employee performance: A Case Study of HFC Bank (GHANA) Ltd". Pp. 15-17

Cooke F L., (2000), "Human Resource Strategy to improve Organizational Performance: A route for British firms", Working Paper No 9 EWERC, Manchester School of Management

Dobson, P. C. and Toh, M. (1998), "Creating a learning organization: training and development in British Steel"s universal beam mill", Total Quality Management, 9, 4/5, pp 66-70.

Isyaku, I.A. (2000), Training and retraining of Teachers through Distance Education. National Workshop on Distance Education Held at Abuja Nigeria. pp 27-29.

Kenney et al, (1992), Management Made Easy, 1st ed. South Carolina: Omron Publishers.Kanungo, R.N., (1982), "Measurement of job and work involvement", Journal of Applied Psychology, Vol; 77, Pp. 341-349.

Nadler, L. \& Nadler, Z. (1998). Developing Human Resource (3rd ed.). San Francisco: Jossey - Bass Publisher

$\mathrm{Ng}$, Y. C. and Siu, N. Y. M. (2004), "Training and enterprise performance in transition: evidence from China", International Journal of Human Resource Management, 15, 4/5, pp 878-94.

Niazi, A.S. (2011), "Training and Development Strategy and Its Role in Organizational Performance," Journal of Public Administration and Governance, 1(2), $42-57$.

Oguntimehin, A. (2001). Teacher effectiveness: Some practical strategies for successful implementation of universal basic education in nigeria, African Journal of Educational Management. 9 (1).

Peteraf, M. A. (1993), "The Cornerstones of Competitive Advantage: A Resource-Based View," Strategic Management Journal, 14(3), 179-192.

Sheeba Hamid (2011), "A Study of Effectiveness of Training and Development Programmes of UPSTDC, India - An analysis", South Asian Journal of Tourism and Heritage, Vol.4 (1).

Stavrou, E., Brewster, C., and Charalambous, C. (2004), 'Human Resource Management as a Competitive Tool in Europe,' working paper, London: Henley College.20. Tyson, S. 